\title{
Molecular recognition of glyconanoparticles by RCA and $E$. coli K88 - designing transports for targeted therapy
}

\author{
Amed Gallegos-Tabanico1, Jose A. Sarabia-Sainz ${ }^{2 凶}$, H. Manuel Sarabia-Sainz ${ }^{3}$, \\ Roberto Carrillo Torres ${ }^{1}$, Ana M. Guzman-Partida4, Gabriela Ramos-Clamont Monfort ${ }^{4}$, \\ Erika Silva-Campa2, Alexel J. Burgara-Estrella2, Aracely Angulo-Molina2, \\ Mónica Acosta-Elias², Martín Pedroza-Montero² and Luz Vazquez-Moreno ${ }^{4}$
}

1Departamento de Física, Universidad de Sonora, Hermosillo, Sonora, 83000, México; 2Departamento de Investigación en Física, Universidad de Sonora, Hermosillo, Sonora, 83000, México; ${ }^{3}$ Departamento de Investigación y Posgrado en Alimentos (DIPA Universidad de Sonora, Hermosillo, Sonora, 83000, México; ${ }^{4}$ Laboratorio de Bioquímica de Proteínas y Glicanos, Coordinación de Ciencia de los Alimentos, Centro de Investigación en Alimentación y Desarrollo A.C., Hermosillo Sonora 83304, México

The targeted drug delivery has been studied as one of the main methods in medicine to ensure successful treatments of diseases. Pharmaceutical sciences are using micro or nano carriers to obtain a controlled delivery of drugs, able to selectively interact with pathogens, cells or tissues. In this work, we modified bovine serum albumin (BSA) with lactose, obtaining a neoglycan (BSA-Lac). Subsequently, we synthesized glyconanoparticles (NPBSA-Lac) with the premise that it would be recognized by microbial galactose specific lectins. NPBSA-Lac were tested for bio-recognition with adhesins of E. coli K88 and Ricinus communis agglutinin I (RCA). Glycation of BSA with lactose was analyzed by electrophoresis, infrared spectroscopy and fluorescence. Approximately 41 lactoses per BSA molecule were estimated. Nanoparticles were obtained using water in oil emulsion method and spheroid morphology with a range size of 300-500 nm was observed. Specific recognition of NPBSA-Lac by RCA and E. coli K88 was displayed by aggregation of nanoparticles analyzed by dynamic light scattering and atomic force microscopy. The results indicate that the lactosylated nanovectors could be targeted at the $E$. coli K88 adhesin and potentially could be used as a transporter for an antibacterial drug.

Key words: bovine serum albumin; neoglycan; nanoparticles; drug delivery; bio-recognition

Received: 07 July, 2017; revised: 26 September, 2017; accepted: 05 October, 2017; available on-line: 16 December, 2017

e-mail: andreisarabia@gmail.com

Abbreviations: BSA, bovine serum albumin; BSA-Lac, lactosylated albumin; NPBSA, albumin nanoparticles; NPBSA-Lac, lactosylated nanoparticles

\section{INTRODUCTION}

Currently, different systems for targeted drug delivery based on inorganic and organic compounds are applied. Recent efforts are focused in designing functionalized carriers for the delivery of therapeutic agents to specific molecular targets expressed in tissues, cells or pathogenic microorganisms (de Jesús Valle et al., 2016). There are different alternatives of therapeutic products approved for clinical use that improve the therapy, however nanotechnology accompanied by the design and synthesis of several biocompatible materials has driven the progress and innovation in drug delivery systems. "Smart polymers" with desirable shape and size, biodegradable, biocompatible and targeting specific tissues are currently the starting points in medicine and health care research (Kratz, 2008).

Albumin is emerging as a new alternative in the targeted therapy because it has several advantages, such as non-toxic, biodegradable and low allergenic activity. In addition, albumin particle synthesis is easy and reproducible, while BSA possesses multiple functional groups that can be used for conjugation of specific targeting molecules (Kratz, 2008). Moreover, the Food and Drug Administration approved the use of albumin nanoparticles (NP) for drug delivery in human patients (Dandagi, Mastiholimath et al., 2006).

Regardless of the progress in design and synthesis of drugs, some therapeutic agents fail because they do not reach the tissue or the targeted-cell. The use of nanospheres, nanocapsules, polymeric micelles, liposomes, dendrimers and ligand conjugates are some of the options to increase the percentage of success (Sahoo \& Labhasetwar, 2003). An active-drug targeting includes the use of ligands to direct the interaction of carriers to many biological targets, represented by self-molecules differentially expressed on damaged cells or in pathogenic agents ( $\mathrm{Xu}$ et al., 2011). In this context, carbohydrates are the first line of contact for any pathogen or cell. The specific protein-carbohydrate interactions mediates multiple biological processes including cell signaling, molecular recognition, immunity and infection processes (Sharon \& Lis, 2004; Reichardt et al., 2013; Yilmaz \& Becer, 2015). Therefore, we note the importance to design platforms conjugated with carbohydrates capable of interacting with biological targets for a better biorecognition.

In bacterial infections, the crucial stage is adhesion and most of the time this process is mediated by carbohydrate-protein interactions which involve bacterial proteins and host tissue carbohydrates (Sattin \& Bernardi, 2016). These bacterial proteins are called adhesins and are either located on the bacterial surface or as a part of appendages, such as pili or fimbriae (Berne et al., 2015). Most of bacteria have multiple adhesins with different carbohydrate specificities. For example, uropathogenic strains of Escherichia coli can bind to the mannose component (Man $\alpha 1-3(\operatorname{Man} \alpha 6)$ Man) in the urinary tractand P-fimbriated E. coli adheres to galactose residues present in the upper part of the kidney (Esko \& Sahron, 2009).

Other bacteria, like Campylobacter jejuni, Mycobacterium tuberculosis and Streptococcus pneumonia, can specifically bind 
to fructose residues of the intestine cells, neuraminic acid in the respiratory epithelium and $\mathrm{N}$-acetyl glucosamine in the respiratory tract, respectively (Esko \& Sahron, 2009). According to Eissa and coworkers (2016), when lactosylated NP were exposed to $E$. coli, adhesion was mainly observed through binding of the galactose and bacterial adhesins. Based on this kind of bio-recognition, particles functionalized with carbohydrates at their surfaces have been reported to exhibit anti-infective actions toward different classes of bacteria (Sarabia-Sainz et al., 2015; Eissa et al., 2016).

Strains of enterotoxigenic Escherichia coli that express K88 fimbriae (E. coli K88) recognize galactose residues present in enterocytes in mammalian cells (González-Ortiz et al., 2014). These bacteria are a perfect model to study the feasibility of glyco-nanomaterials in different processes in the field of medicine (Miura et al., 2016; Sattin \& Bernardi, 2016). Previously, we reported that the modification of BSA with lactose (BSA-Lac) through thermal glycation promotes recognition of the bacterial adhesin (Sarabia-Sainz et al., 2011). In addition, the BSALac microspheres were recognized by partially purified K88 adhesin of E. coli K88 (Sarabia-Sainz et al., 2015). The aim of this work was to synthesize nanoparticles using glycated BSA and assess its ability to specifically interact with bacterial adhesins as a strategy for potential applications, such as targeted carrier of antibacterial drugs to treat infections.

\section{MATERIALS AND METHODS}

Materials. All reagents used were of analytical grade. Bovine serum albumin (BSA), lactose (Lac), glutaraldehyde $(25 \%)$ and $\operatorname{Span}^{\circledR} 80$ were purchased from Sigma-Aldrich (St. Louis, MO, USA). Ricinus communis agglutinin (RCA) was purchased from the Vector Lab (Burlingame, CA, USA). Enterotoxigenic E. coli $\mathrm{K} 88+$, isolated from pigs, was donated by Dr. Carlos Eslava from the Universidad Nacional Autónoma de México (UNAM).

Lactosylation of BSA. Modification of albumin with lactose (BSA-Lac) was carried out through a process of reaction resulting from glycation, described in 2011 by Sarabia-Sainz and coworkers (2011).

Characterization of BSA-Lac. Polyacrylamide Gel Electrophoresis. Molecular mass of BSA-Lac was analyzed by electrophoresis under denaturing and reducing conditions using 10\% polyacrylamide gels according to Laemmli (1970). Broad range SDS-PAGE molecular weight standards (myosin $(200 \mathrm{kDa}), \beta$-galactosidase $(116.2 \mathrm{kDa})$, phosphorylase b $(97.4 \mathrm{kDa})$, bovine serum albumin $(66.2 \mathrm{kDa})$, ovalbumin $(45 \mathrm{kDa})$, carbonic anhydrase $(31 \mathrm{kDa})$ ) from BioRad (Hercules, CA, USA) were used. Protein load was $10 \mu \mathrm{g}$ and gel was stained with Coomassie brilliant blue R. Relative molecular mass of the sample was estimated by comparison with the molecular weight standards, using a Molecular Imager ${ }^{\circledR}$ Gel Doc $^{\text {TM }} \mathrm{XR}+$ System with Image Lab ${ }^{\text {TM }}$ Software (Image Lab 3.0, BioRad). Estimated molecular mass increase of BSA-Lac was used to determine the units of lactose added to the protein. In this experiment, untreated BSA was used as control.

Tryptophan intrinsic fluorescence (Trp-IF). TrpIF of BSA-Lac was analyzed using a Cary Eclipse fluorescence spectrophotometer (Agilent, Santa Clara, CA, USA) with a 1 -cm-path length quartz cuvette at $25^{\circ} \mathrm{C}$. BSA-Lac solutions were prepared in $10 \mathrm{mM} \mathrm{KH}_{2} \mathrm{PO}_{4} /$ $\mathrm{K}_{2} \mathrm{HPO}_{4}, 0.9 \% \mathrm{NaCl}$ (PBS) at $\mathrm{pH} 7.2$ and adjusted to 0.1 absorbance units at $280 \mathrm{~nm}$ (Plotnikova et al., 2016).
The assay was carried out with excitation at $295 \mathrm{~nm}$ and emission scanning in the range of 300-400 nm. Trp-IF was expressed as relative fluorescence in arbitrary units (AU). All assays were done in triplicate.

Fourier Transform Infrared (FT-IR) spectroscopy. The analysis of functional groups of BSA-Lac was made by FT-IR (Guler et al., 2016). Infrared spectra were recorded using a FT-IR spectrometer with UATR module (Spectrum Two, Perkin Elmer, USA) at a resolution of $4 \mathrm{~cm}^{-1}$ in the range of $500-4000 \mathrm{~cm}^{-1}$. All assays were done in triplicate.

Synthesis of albumin nanoparticles. BSA-Lac nanoparticles (NPBSA-Lac) were prepared according to Sarabia-Sainz and coworkers (2012) with slight modifications. Span ${ }^{\circledR} 80$ and glutaraldehyde saturated toluene (GST) were used as a surfactant and cross-linking agents, respectively. Briefly, $1 \mathrm{~mL}$ of aqueous solution containing $10 \%$ BSA-Lac was added drop by drop to $25 \mathrm{~mL}$ of mineral oil containing $100 \mu \mathrm{L}$ of $\operatorname{Span}^{\circledR}$ 80, which was kept in stirring at $8000 \mathrm{rpm}$ using a homogenizer. After $30 \mathrm{~min}, 100 \mu \mathrm{L}$ of GST was added. The emulsion process was carried out for 2 hours by continuous stirring and subsequently the NPBSA-Lac was obtained by centrifugation at $1644 \times g$ for $20 \mathrm{~min}$. Finally, the NPBSA-Lac was washed with hexane and dried at room temperature. The same procedure as above was used for NPBSA control synthesis.

Characterization of nanoparticles. Dynamic Light Scattering (DLS). DLS is an optical technique used to determine the autocorrelation fluctuations of particles and molecules in colloidal systems. Dynamic fluctuations are proportional to coefficient diffusion and therefore to hydrodynamic dimension (Dominguez-Medina et al., 2016). Size distribution of NPBSA and NPBSA-Lac were measured by Dynamic Light Scattering (DLS) (Thao le et al., 2016) using a Zetasizer Nano ZS 90 (Malvern Instruments Ltd., Malvern, UK). Samples were diluted with PBS $(1 \mathrm{mg} / \mathrm{mL})$ at $\mathrm{pH} 7.2$. The experiments were performed at $25^{\circ} \mathrm{C}$ using a measuring angle of $90^{\circ}$. All measurements were done in triplicate.

Zeta potential. The zeta potential of nanoparticles was determined by laser Doppler anemometry (Kim et al., 2016) using a Zetasizer Nano ZS 90 (Malvern Instruments Ltd., Malvern, UK). The measurements were performed at $25^{\circ} \mathrm{C}$. The nanoparticles were dispersed in PBS $(1 \mathrm{mg} / \mathrm{mL})$ at $\mathrm{pH}$ 7.2. All the measurements were done in triplicate.

Nanoparticle morphology. Scanning Electron Microscopy (S.E.M.) according to (Kim et al., 2016) was performed to visualize the surface morphology characteristics of the nanoparticles. Lyophilized sample was lightly dusted onto the carbon tape of the SEM stub surface and was studied with a field emission SEM (JSM-7800F, JEOL, Japan) at $0.6 \mathrm{kV}$ of acceleration voltage and magnification was $20000 \times$.

Trials of biorecognition. Recognition with RCA. For lectin recognition, NPBSA or NPBSA-Lac nanoparticles (1 $\mathrm{mg}$ of each) were suspended in $3 \mathrm{~mL}$ of PBS, $\mathrm{pH}$ 7.2. Then, a solution of RCA was added at different concentrations $(0.3,1$ and $3.5 \mu \mathrm{g} / \mathrm{mL})$ and incubated for 30 minutes. Interaction was measured by the increase in size distribution of the nanoparticles by DLS, as described above.

Recognition with bacteria. Enterotoxigenic E. coli, that express the K88 fimbrial adhesin with specificity for terminal galactose, were used as the cell model to evaluate the recognition of NPBSA-Lac (Sarabia-Sainz et al., 2013). The strains of E. coli K88 were grown in CFA agar at $37^{\circ} \mathrm{C}$ for $24 \mathrm{~h}$. Later, a suspension of bacteria in 
PBS was prepared and adjusted to 0.2 units of optical

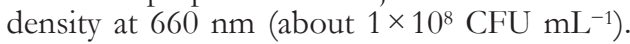

General procedure for bacterial recognition was similar for NPBSA and NPBSA-Lac. Bacterial suspension was mixed with NPBSA-Lac suspensions $(0.4 \mathrm{mg} / \mathrm{mL}$ in PBS) as follows: $10 \mathrm{~mL}$ of nanoparticles $+5 \mathrm{~mL}$ of bacterial suspension, $10 \mathrm{~mL}$ of nanoparticles $+1 \mathrm{~mL}$ of bacterial suspension. The recognition was promoted for $30 \mathrm{~min}$ at $25^{\circ} \mathrm{C}$. The interaction was measured by DLS, as described above.

The morphology of the bacteria and their interaction with NPBSA-Lac was visualized with Atomic Force Microscopy (AFM). Two $\mathrm{mL}$ of the bacterial suspension were mixed with $50 \mu \mathrm{L}$ of NPBSA-Lac (1 $\mathrm{mg} /$ $\mathrm{mL}$ ) and incubated for $30 \mathrm{~min}$ at $25^{\circ} \mathrm{C}$. Next, $10 \mu \mathrm{L}$ of this mixture were dropped and immobilized by drying on a glass slide for 30 minutes at $25^{\circ} \mathrm{C}$. The samples were extensively rinsed with deionized water, dried and placed directly under the AFM. The samples were analized by AFM (XE-Bio system, Park Systems Corp, Suwon, Korea) coupled to an inverted microscope (Nikon Ti-E, Nikon Instruments Inc. USA.) The images were obtained in the non-contact mode using NCHR cantilevers (force constant 10-130 N/m). The shape analysis was performed by scans of $50 \times 50 \mu \mathrm{m}$ for each specimen, followed by scans of $35 \times 35 \mu \mathrm{m}$, and then scans of $10 \times 10 \mu \mathrm{m}$. Finally, the bacterial structure and nanoparticle interactions were analyzed using scan images of $5 \times 5 \mu \mathrm{m}$. The number of scanning points was 256 . Images and their profiles were analyzed in $2 \mathrm{D}$ and $3 \mathrm{D}$ modes with the XEI software version 1.8 , provided by Park Systems.

\section{RESULTS AND DISCUSSION}

\section{Characterization of BSA-Lac}

The glycation process, also named non-enzymatic glycosylation, is a reaction between the free amino groups of proteins and carbonyl groups of reducing sugars known as the Maillard reaction (Singh et al., 2014). This coupling reaction of protein with sugar produces neoglycans. Previous reports indicate that glycation is favored by temperatures above $60^{\circ} \mathrm{C}$, alkaline $\mathrm{pH}$, and influenced by moisture and reaction time (Ledesma-Osuna et al., 2009; Sarabia-Sainz et al., 2011). Other factors, such as water activity, intrinsic properties of protein and sugar, and the amino group-reducing sugar ratio, influence the

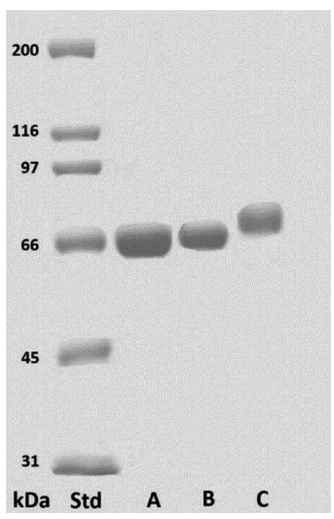

Figure 1. SDS-PAGE profiles of BSA.

BSA treated under similar conditions of glycation but without lactose (BSAt) and BSA-Lac. Lane Std, molecular mass standards; Lane A, BSA; Lane B, BSAt; Lane C, BSA-Lac. yields and types of the Maillard reaction products. In this work, the glycation of BSA with lactose was conducted at a 1:200 molar ratio (BSA: lactose) at $100^{\circ} \mathrm{C}$ for $30 \mathrm{~min}$. Then, physicochemical properties, as change in molecular mass and structure, of the glycoconjugates were evaluated by SDS-PAGE, FT-IR and Trp-IF.

\section{Molecular mass analysis by SDS-PAGE}

SDS-PAGE was used to determine the extent of BSA glycation. As a control, we used untreated BSA (BSA) and BSA treated in a similar process to glycation but in the absence of lactose (BSAt). Figure 1 shows a reduction in the electrophoretic migration of BSA-Lac when compared to BSA and BSAt. Lanes A and B show the typical molecular mass of $66 \mathrm{kDa}$ corresponding to $\mathrm{BSA}$, while BSA-Lac exhibited $81 \mathrm{kDa}$, representing an increase of $22 \%$ in the molecular mass (Fig. 1, lane C). This result suggests that lactosylation, under these conditions, modifies the mass of BSA. This effect could be due to the addition of 41 lactose molecules, calculated according to Ledesma-Osuna and coworkers (2008).

\section{Analysis of structure modification by Trp-IF}

In order to characterize structural changes in BSA induced by glycation, fluorometric studies were performed. Fluorescence of aromatic aminoacids (phenylalanine, tyrosine and mainly tryptophan) is sensitive to the polarity of its local environment as a result of the protein conformational changes. The emission wavelength and intensity yields of fluorescence in the protein decrease when fluorophores interact with quenching agents or polar solvents. Change in the emission spectra that are characteristic for a given protein provide information about conformation and tertiary structure of that protein (Tang et al., 2012). Figure 2 shows a reduction in the fluorescence emission intensity of BSA-Lac when compared to BSA and BSAt. A previous report indicated that diminished fluorescence intensity after glycation is attributed to the shielding effect of carbohydrates binding to proteins (Jimenez-Castano et al., 2007). Also, Jian and coworkers (2016) reported that carbohydrates can act as quenching agents that decrease the fluorescence emission of proteins. However, it is important to consider that the fluorescence intensity of proteins is similarly decreased during the heating process (Duy \& Fitter, 2006), as we observed in BSAt. Therefore, the strong fluorescence quenching acivity of BSA-Lac can be attributed to a combination of glycation and thermal treatment.

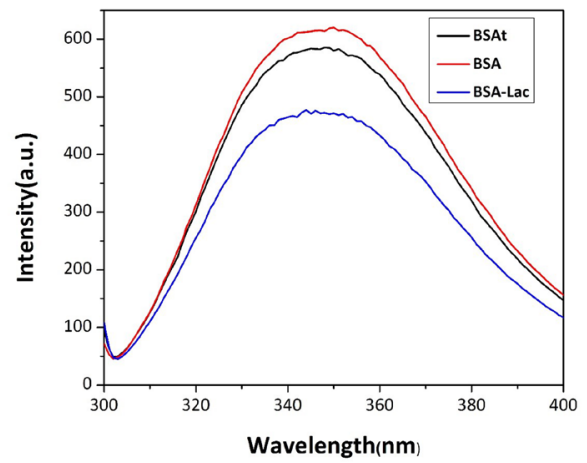

Figure 2. Intrinsic tryptophan fluorescence.

BSA (red line); BSA treated under similar conditions of glycation but without lactose (BSAt) (black line); BSA-Lac (Blue line). 


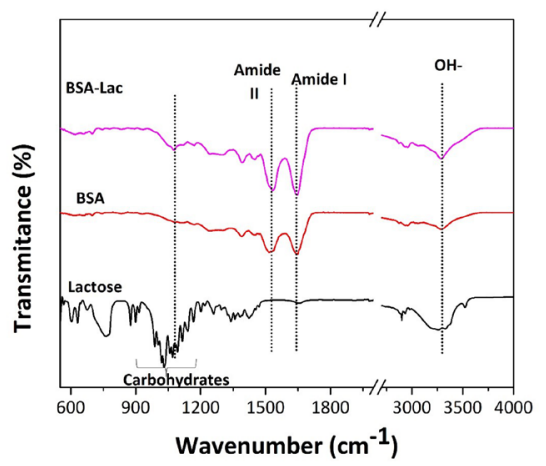

Figure 3. FT-IR of BSA (black line) and BSA-Lac.

Insert in the figure represents the Amadori rearrangement between sugar and protein.

\section{Chemical structure by FT-IR analysis}

FT-IR analysis is an effective method to obtain information related to the composition and chemical structure of materials. Secondary structure of proteins is analyzed by their specific wavelength absorption. Infrared spectra of BSA and its glycation products were analyzed in order to confirm conjugation with lactose. Figure 3 shows the FT-IR spectra of BSA, BSA-Lac and lactose. BSA-Lac spectrum presented an increase in amide vibrational bands (amide I, II and A), which are characteristic of an infrared spectrum of proteins (Arrondo et al., 1993; Arrondo \& Goñi, 1999). The C-N bond formed during glycation might contribute to the increased vibration intensity of the Amide I $\left(1600-1700 \mathrm{~cm}^{-1}\right)$ and Amide II (1510-1580 $\mathrm{cm}^{-1}$ ) bands (Jian et al., 2016). In addition, BSA-Lac shows intensity increment in the band of amide A (3225 and $3280 \mathrm{~cm}^{-1}$ ), which can be attributed to the lactose hydrogens, and for this reason this band is very sensitive to hydrogen bond formation (Arrondo et al., 1993; Arrondo \& Goñi, 1999). Additionally, forBSA-Lac a new peak at 1000-1250 $\mathrm{cm}^{-1}$ emerges which is reported as a fingerprint region of the disaccharides (Jian et al., 2016) and this peak is observed in the lactose spectra. Based on the increase in molecular mass, the quenching effect and the increase of vibration intensity of bands associated with glycation, we assume that BSA was successfully conjugated to lactose to form a new glycation product.

\section{Morphology, particle size and zeta potential of NP}

Once glyco-conjugation between BSA and lactose was confirmed, the next step was to perform the synthesis and characterization of BSA nanoparticles (NPBSA) as a control, and BSA-Lac nanoparticles (NPBSA-Lac). In order to accomplish this purpose, we determined the nanoparticle morphology and size by S.E.M. and DLS, respectively. Figures $4 \mathrm{~A}$ and $4 \mathrm{C}$ show the S.E.M. analysis of NPBSA and NPBSA-Lac. Both samples present spheroidal shape with a smooth surface. The mean size and polydispersity of nanoparticles were confirmed by DLS (Fig. 4B and 4D). Size range was slightly greater for NPBSA with a mean size of $459 \pm 29.28 \mathrm{~nm}$, while NPBSA-Lac presented a mean size of $405 \pm 22.03 \mathrm{~nm}$.

The zeta potential of NPBSA and NPBSA-Lac was measured to determine their surface charge. This parameter is important for the stability of the particles in suspension. In this study, all nanoparticles synthesized had a mean value of $-40 \mathrm{mV}$. This Z-potental value indicates a good stability in the system and prevents formation of aggregates in a colloidal solution (Patil et al., 2007). This
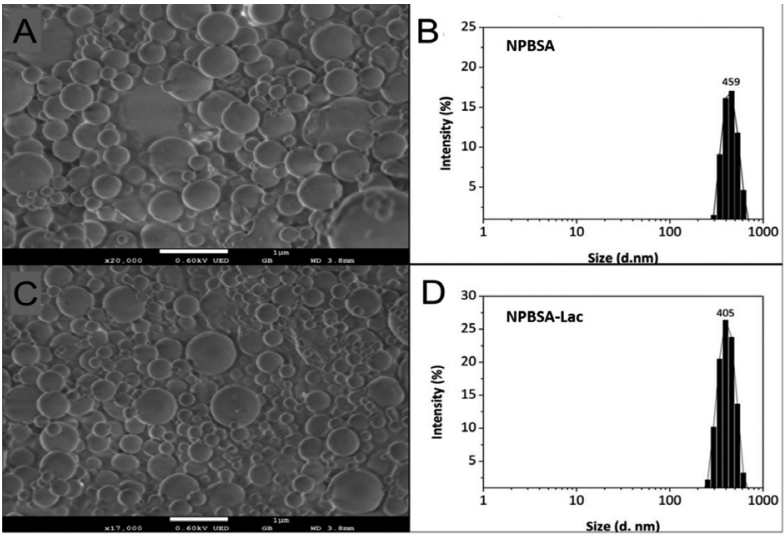

Figure 4. Characterization of nanoparticles by S.E.M. and DLS. (A) and (B) show the morphology and size distribution, respectively, of nanoparticles synthetized with BSA (NPBSA). (C) and (D) show the morphology and size distribution of nanoparticles synthetized with BSA-Lac (NPBSA-Lac), respectively.

result was consistent with the stable nanoparticle dispersion observed, both in water or PBS (data not shown).

Recognition of NPBSA-Lac by soluble lectin assay. The major aim of this work was to synthetize particles of BSA conjugated with lactose, with the ability to promote biorecognition of specific receptors for lactose (galactose $\beta$ (1-4) glucose). Glycation of BSA involves coupling of the protein through glucose (reducing end), leaving galactose available for biological recognition. Previous work demonstrated that glycation with monomers of reducing sugars, such as glucose or galactose, did not showed recognition either galactose or glucose by specific lectins (Ledesma-Osuna et al., 2008). After the synthesis of NPBSA-Lac, to verify that the galactose residues
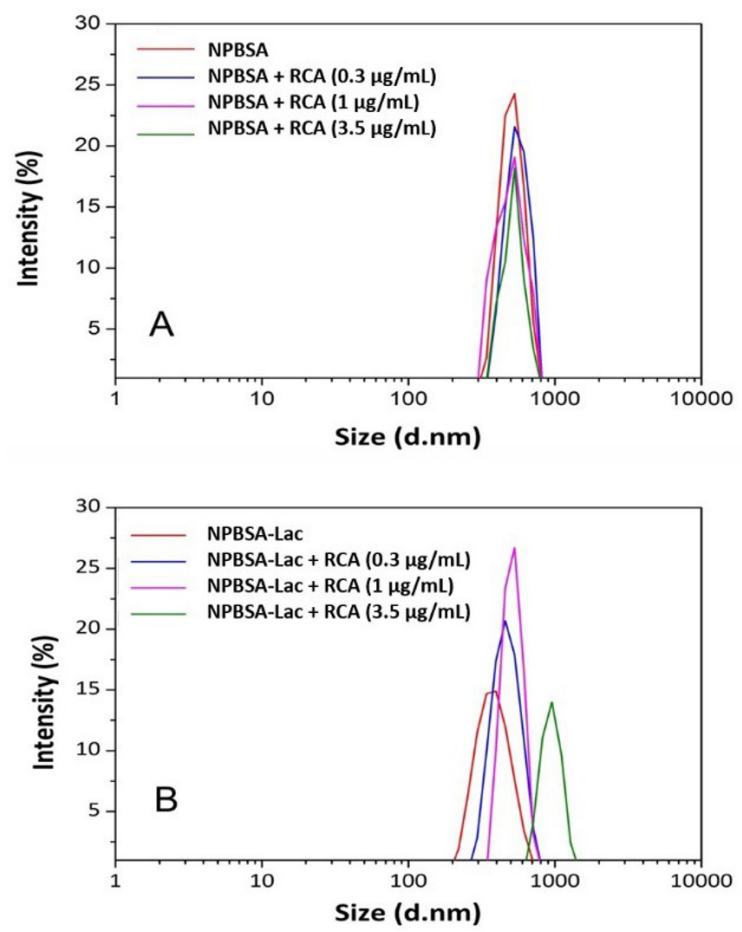

Figure 5. Size distribution measured by DLS of nanoparticles treated with several amounts of RCA.

(A) shows the size distribution of NPBSA incubated with RCA. (B) shows the change in size distribution of NPBSA-Lac incubated with RCA. Measurements were performed separately, obtaining 20 scans in each sample, and were repeated 6 times. 

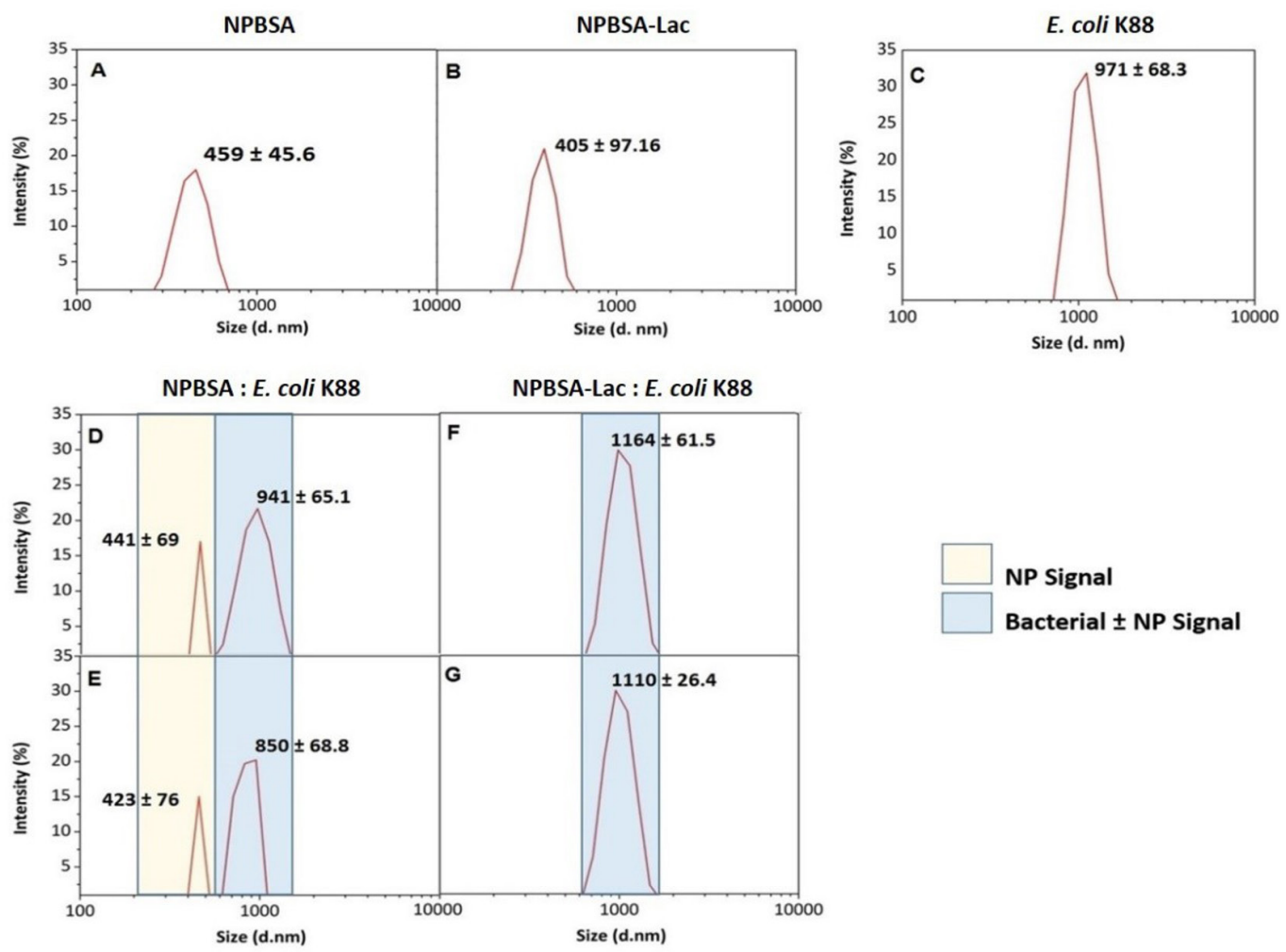

NP Signal

Bacterial \pm NP Signal

Figure 6. Size distribution by DLS of $E$. coli K88 with NPBSA-Lac and NPBSA

(A) NPBSA; (B) NPBSA-Lac; (C) E. coli K88; (D) NPBSA (4 mg) + E. coli $\left(5 \times 10^{8}\right.$ CFU); (E) NPBSA (4 mg) + E. coli (1 x $10^{8}$ CFU); (F) NPBSA-Lac (4 $\mathrm{mg})+$ E. coli $\left(5 \times 10^{8} \mathrm{CFU}\right) ;(\mathbf{G}) \mathrm{NPBSA}-\mathrm{Lac}(4 \mathrm{mg})+$ E. coli $\left(1 \times 10^{8} \mathrm{CFU}\right)$

were structurally intact and available for biological interactions, the NPBSA-Lac were exposed to bivalent galactose-binding lectin (RCA). The aggregates' size of NPBSA-Lac resulting from the interactions with RCA was measured by DLS. The size of the control NPBSA was not affected by incubation with RCA (Fig. 5A). However, when NPBSA-Lac were incubated with RCA, an increase in the mean size due to aggregate formation was observed (Fig. 5B). When NPBSA-Lac were incubated with several concentrations of RCA, progressively large aggregates were measured (Wang et al., 2011). Valtola and coworkers (Valtola et al., 2014) reported that similar aggregates were formed by the interaction of lectins and glycosylated nanoparticles. Thus, the size increase in NPBSA-Lac can be related to aggregation of nanoparticles with lectins, due to the interactions of RCA and galactose exposed on the surface of the NPBSA-Lac. When the concentration is increased from $0.3 \mu \mathrm{g} / \mathrm{mL}$ to $3.5 \mu \mathrm{g} / \mathrm{mL}$ of lectin, a $500 \mathrm{~nm}$ increase in the diameter size of NPBSA-Lac aggregates was observed.

\section{Bacteria-nanoparticle interaction analyzed by DLS and Atomic Force Microscopy (AFM)}

As we described before, NPBSA-Lac presented galactose residues available for interaction with receptors. The next step was to determine the biological recognition of NPBSA-Lac by a cellular model with specific adhesion to galactose. In this context, E. coli express the K88 adhesin that exhibits affinity to terminal galactose residues, whereby it is used as a model for the glyconanoparticle-cell recognition. The size distribution was evaluated for the E. coli alone and in the presence of nanoparticles. Figure 6 shows that by the DLS analysis, NPBSA and NPBSA-Lac are $459 \pm 45.6$ and $405 \pm$
$97.16 \mathrm{~nm}$ in size, respectively, while E. coli is $971 \pm 68.3$ nm (Fig. 6, A-C). When the suspensions of E. coli and NPBSA were tested by DLS, two peaks with distribution size for nanoparticle $(459 \pm 45.6 \mathrm{~nm})$ and bacteria $(971 \pm 68.3 \mathrm{~nm}$ ) were observed (Fig. 6, D-E); this is attributed to the null interaction between the bacteria and particles. In contrast, when the suspension of NPBSA-Lac and E. coli is analyzed, only one peak was detected with sizes ranging from $1164 \pm 61.5$ to $1110 \pm 26$ (Fig. 6, F-G). It is remarkable that in these samples, the band corresponding to NPBSA-Lac (mean size of $400 \mathrm{~nm}$ ) is not found. This result indicates that the NPBSA-Lac are attached to the body of the bacteria due to the adhesin-carbohydrate biorecognition. The specific binding between NPBSA-Lac with bacteria was verified by AFM analysis. Figure 7 shows particles (size range of $300-500 \mathrm{~nm})$ attached to the bacillus $(1.5 \mu \mathrm{m} \times 2.5$ $\mu \mathrm{m}$ of size). The AFM image confirms the capability of

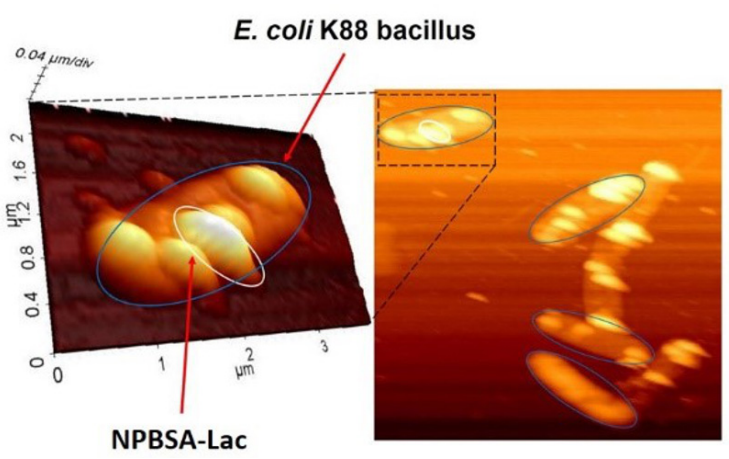

Figure 7. AFM image of the $E$. coli $\mathrm{K} 88$ bacillus incubated with NPBSA-Lac. 
our glyconanosystems (NPBSA-Lac) to be specifically recognized by bacteria through a selective K88 adhesin. Kheireddine and coworkers (El-Boubbou et al., 2007) reported a TEM image where the glyco-nanoparticles can establish specific interaction with $E$. coli strains forming complexes, observing nanoparticles on the body, the lateral ends and along pili of the bacterial cells. Also, Lin and colleagues (Lin et al., 2002) reported selective binding of mannose-modified Au nanoparticles to type 1 pili on the body of $E$. coli. These results allow the potential implementation of nanosystems for application in selective drug delivery and anti-adherent therapy to combat pathological events that take place through carbohydrate-lectin interactions.

\section{CONCLUSIONS}

The nanoparticles synthetized using lactosylated bovine serum albumin were biorecognized by Ricinus communis lectins and E. coli $\mathrm{K} 88$, showing a clear interaction. These results indicate that lactosylated nanoparticles could be used as potential targeted vectors in drug transport.

\section{Author Contributions}

Amed Gallegos-Tabanico: preparation of nanoparticles, recognition assays, and integration and editing of document. Hector Sarabia-Sainz: fluorescence analysis and writing parts of the manuscript. Roberto Carrillo: SEM analysis and writing parts of the manuscript. Ana Guzman-Partida: recognition assay and data analysis. Gabriela Ramos-Clamont Montfort: data analysis, writing parts of the manuscript and discussion. Erika Silva-Campa and Alexel J. Burgara-Estrella: AFM characterization, analysis and writing parts of the manuscript. Mónica A. Acosta-Elias: FTIR analysis. Luz Vazquez-Moreno, Martín R. Pedroza-Montero (leaders of the project): conception and experimental design, J. Andre-i Sarabia-Sainz: revising of the manuscript and final approval.

\section{Conflicts of Interest}

The authors declare no conflict of interest.

\section{Acknowledgements}

We are grateful to the National Council of Sciences and Technology of Mexico and to CONACYT for their financial support of this research, under Project PDCPN248982, as well as for a scholarship for postgraduate studies.

\section{REFERENCES}

Arrondo JLR, Goñi FM (1999) Structure and dynamics of membrane proteins as studied by infrared spectroscopy. Progress Biophys Mol Biol 72: 367-405. https://doi.org/10.1016/S0079-6107(99)00007-3

Arrondo JLR, Muga A, Castresana J, Goñi FM (1993) Quantitative studies of the structure of proteins in solution by Fourier-transform infrared spectroscopy. Progress Biophys Mol Biol 59: 23-56. https:// doi.org/10.1016/0079-6107(93)90006-6

Berne CD, Hardy A, Brun GG (2015) Adhesins involved in attachment to abiotic surfaces by gram-negative bacteria. Microbiol Spectrum 3: 1-45. doi: 10.1128/microbiolspec.MB-0018-2015

Dandagi PM, Mastiholimath VS, Patil MB, Gupta MK (2006) Biodegradable microparticulate system of captopril. Int J Pharm 307: 8388. doi:10.1016/j.ijpharm.2005.10.025

de Jesús Valle MJ, López D, Díaz M, Salicio V, Sánchez Navarro A (2016) Development and in vitro evaluation of a novel drug delivery system (albumin microspheres containing liposomes) applied to vancomycin. J Pharm Sci 105: 2180-2187. http://dx.doi.org/10.1016/j. xphs.2016.05.009
Dominguez-Medina S, Chen S, Blankenburg J, Swanglap P, Landes CF, Link S (2016) Measuring the hydrodynamic size of nanoparticles using fluctuation correlation spectroscopy. Ann Rev Physic Chem 67: 489-514. https://doi.org/10.1146/annurev-physchem-040214-121510

Duy Cand Fitter J (2006) How aggregation and conformational scrambling of unfolded states govern fluorescence emission spectra. Biophys I 90: 3704-3711. 10.1529/biophysj.105.078980

Eissa AM, Abdulkarim A, Sharples GJ, Cameron NR (2016) Glycosylated nanoparticles as efficient antimicrobial delivery agents. Biomacromol 17: 2672-2679. doi: 10.1021/acs.biomac.6b00711

El-Boubbou K, Gruden C, Huang X (2007) Magnetic glyco-nanoparticles: a unique tool for rapid pathogen detection decontamination and strain differentiation. J Am Chem Soc 129: 13392-13393. doi: 10.1021/ja076086e

Esko J, Sahron N (2009) Microbial lectins: hemagglutinins adhesins and toxins. Essentials of Glyco-Biology 489-500. PMID:20301238

González-Ortiz G, Pérez JF, Hermes RG, Molist F, Jiménez-Díaz R, Martín-Orúe SM (2014) Screening the ability of natural feed ingredients to interfere with the adherence of enterotoxigenic Escherichia coli (ETEC) K88 to the porcine intestinal mucus. Brit J Nutrit 111: 633-642

Guler G, Vorob'ev MM, Vogel V, Mantele W (2016) Proteolytically-induced changes of secondary structural protein conformation of bovine serum albumin monitored by Fourier transform infrared (FTIR) and UV-circular dichroism spectroscopy. Spectrochim Acta A Mol Biomol Spectrosc 161: 8-18. doi: 10.1016/j.saa.2016.02.013

Jian W, He J, Sun Y, Pang J (2016) Comparative studies on physicochemical properties of bovine serum albumin-glucose and bovine serum albumin-mannose conjugates formed via Maillard reaction. LWT-Food Sci Technol 69: 358-364

Jimenez-Castano L, Villamiel M, López-Fandiño R (2007) Glycosylation of individual whey proteins by Maillard reaction using dextran of different molecular mass. Food Hydrocolloids 21: 433-443. https:// doi.org/10.1016/j.foodhyd.2006.05.006

Kim B, Lee C, Lee ES, Shin BS, Youn YS (2016) Paclitaxel and curcumin co-bound albumin nanoparticles having antitumor potential to pancreatic cancer. Asian J Pharm Sci 1-7. https://doi. org/10.1016/j.ajps.2016.05.005

Kratz F (2008) Albumin as a drug carrier: design of prodrugs drug conjugates and nanoparticles. I Controlled Release 132: 171-183. doi: 10.1016/j.jconrel.2008.05.010

Laemmli UK (1970) Cleavage of structural proteins during the assembly of the head of bacteriophage T4. Nature 227: 680-685. PMID: 5432063

Ledesma-Osuna AI, Ramos-Clamont G, Vázquez-Moreno L (2008) Characterization of bovine serum albumin glycated with glucose galactose and lactose. Acta Biochim Pol 55: 491-497

Ledesma-Osuna AI, Ramos-Clamont G, Vázquez-Moreno L (2009) Biorecognition of chemically modified bovine serum albumin with lactose prepared under different conditions. I Agric Food Chem 57: 9734-9739. doi: 10.1021/jf9020976

Lin C-C, Yeh Y-C, Yang C-Y, Chen C-L, Chen G-F, Chen C-C, Wu Y-C (2002) Selective binding of mannose-encapsulated gold nanoparticles to type 1 pili in Escherichia coli. I Am Chem Soc 124: 3508-3509. doi: 10.1021/ja0200903

Miura Y, Hoshino Y, Seto H (2016) Glycopolymer nanobiotechnology. Chem Rev 116: 1673-1692. doi: 10.1021/acs.chemrev.5b00247

Patil S, Sandberg A, Heckert E, Self W, Seal S (2007) Protein adsorption and cellular uptake of cerium oxide nanoparticles as a function of zeta potential. Biomaterials 28: 4600-4607. doi: 10.1016/j.biomaterials.2007.07.029

Plotnikova OA, Mel'nikov AG, Mel'nikov GV, Gubina TI (2016) Quenching of tryptophan fluorescence of bovine serum albumin under the effect of ions of heavy metals. Optics and Spectroscopy 120: 65-69. doi: 10.1134/S0030 400X16010148

Reichardt NC, Martín-Lomas M, Penadés S (2013) Glyconanotechnology. Chem Soc Rev 42: 4358-4376. doi: 10.1039/C2CS35427F

Sahoo SK, Labhasetwar V (2003) Nanotech approaches to drug delivery and imaging. Drug Discovery Today 8: 1112-1120. https://doi. org/10.1016/S1359-6446(03)02903-9

Sarabia-Sainz A-I, Ramos-Clamont G, del Carmen Candia-Plata M, Vázquez-Moreno L (2009) Biorecognition of Escherichia coli K88 adhesin for glycated porcine albumin. Int J Biol Macromol 44: 175-181. https://doi.org/10.1016/j.ijbiomac.2008.11.009

Sarabia-Sainz A-I, Sarabia-Sainz H, Montfort G, Mata-Haro V, Guzman-Partida A, Guzman R, Garcia-Soto M, Vazquez-Moreno L (2015) K88 Fimbrial Adhesin targeting of microspheres containing gentamicin made with albumin glycated with lactose. Int J Mol S i 16: 22425 . doi: 10.3390/ijms160922425

Sarabia-Sainz A-I, Ramos-Clamont G, Winzerling J, Vázquez-Moreno L (2011) Bacterial recognition of thermal glycation products derived from porcine serum albumin with lactose. Acta Biochim Pol 58: 95-100

Sarabia-Sainz AM, Ramos-Clamont G, Lizardi-Mendoza J, Sánchez-Saavedra MDP, Candia-Plata MDC, Guzman RZ, Luce- 
ro-Acuña A, Vazquez-Moreno L (2012) Formulation and characterization of gentamicin-loaded albumin microspheres as a potential drug carrier for the treatment of E. coli $\mathrm{k} 88$ infections. Int J Drug Delivery 4: 209-218. http://www.arjournals.org/index.php/ijdd/index

Sarabia-Sainz HM, Armenta-Ruiz C, Sarabia-Sainz A-I, Guzmán-Partida AM, Ledesma-Osuna AI, Vázquez-Moreno L, Ramos-Clamont Montfort G (2013) Adhesion of enterotoxigenic Escherichia coli strains to neoglycans synthesised with prebiotic galactooligosaccharides. Food Chem 141: 2727-2734. https://doi.org/10.1016/j.foodchem.2013.05.040

Sattin S, Bernardi A (2016) Glycoconjugates and glycomimetics as microbial anti-adhesives. Trends Biotechnol 34: 483-495. https://doi. org/10.1016/j.tibtech.2016.01.004

Sharon N, Lis H (2004) History of lectins: from hemagglutinins to biological recognition molecules. Glycobiology 14: 53R-62R. https://doi. org/10.1093/glycob/cwh122

Singh VP, Bali A, Singh N, Jaggi AS (2014) Advanced glycation end products and diabetic complications. Korean J Physiol Pharmacol 18: 1-14. doi: 10.4196/kjpp.2014.18.1.1

Tang X, Wu Q, Le G, Shi Y (2012) Effects of heat treatment on structural modification and in vivo antioxidant capacity of soy protein. Nutrition 28: 1180-1185. doi: 10.1016/j.nut.2012.03.011
Thao le Q, Byeon HJ, Lee C, Lee S, Lee ES, Choi YW, Choi HG, Park ES, Lee KC, Youn YS (2016) Doxorubicin-bound albumin nanoparticles containing a TRAIL protein for targeted treatment of colon cancer. Pharm Res 33: 615-626. doi: 10.1007/s11095-0151814-z

Valtola L, Rahikkala A, Raula J, Kauppinen EI, Tenhu H, Hietala S (2014) Synthesis and lectin recognition of glycosylated amphiphilic nanoparticles. Eur Polymer J 59: 282-289. https://doi.org/10.1016/j. eurpolymj.2014.07.031

Wang S, Cesca F, Loers G, Schweizer M, Buck F, Benfenati F, Schachner M, Kleene R (2011) Synapsin i is an oligomannose-carrying glycoprotein acts as an oligomannose-binding lectin and promotes neurite outgrowth and neuronal survival when released via glia-derived exosomes. I Neurosci 31: 7275-7290. https://doi. org/10.1523/JNEUROSCI.6476-10.2011

Xu R, Fisher M, Juliano RL (2011) Targeted albumin-based nanoparticles for delivery of amphipathic drugs. Bioconjugate Chem 22: 870878. doi: 10.1021/bc1002295

Yilmaz G, Becer CR (2015) Glyconanoparticles and their interactions with lectins. Polymer Chem 6: 5503-5514. doi: 10.1039/C5PY00089K 